\title{
VARIATIONS OF RADIOCARBON IN TREE RINGS: SOUTHERN HEMISPHERE OFFSET PRELIMINARY RESULTS
}

\author{
F. G. MCCORMAC, ${ }^{l}$ A. G. HOGG, ${ }^{2}$ T. F. G. HIGHAM, ${ }^{2}$ M. G. L. BAILLIE, ${ }^{1}$ J. G. PALMER, ${ }^{3}$ \\ LIMIN XIONG, ${ }^{3}$ J. R. PILCHER, ${ }^{l}$ DAVID BROWN' and S. T. HOPER ${ }^{l}$
}

\begin{abstract}
The Queen's University of Belfast, Northern Ireland and University of Waikato, Hamilton, New Zealand radiocarbon laboratories have undertaken a series of high-precision measurements on decadal samples of dendrochronologically dated oak (Quercus patrea) and cedar (Libocedrus bidwillii) from Great Britain and New Zealand, respectively. The results show a real atmospheric offset of $3.4 \pm 0.6 \%\left(27.2 \pm 4.7{ }^{14} \mathrm{C}\right.$ yr $)$ between the two locations for the interval AD 1725 to $\mathrm{AD}$ 1885, with the Southern Hemisphere being depleted in ${ }^{14} \mathrm{C}$. This result is less than the value currently used to correct Southern Hemisphere calibrations, possibly indicating a gradient in $\Delta^{14} \mathrm{C}$ within the Southern Hemisphere.
\end{abstract}

\section{INTRODUCTION}

A number of studies have demonstrated a measurable difference between the ${ }^{14} \mathrm{C}$ activities of dendrochronologically dated trees between the hemispheres (Lerman, Mook and Vogel 1970; Vogel et al. 1986; Vogel et al. 1993). Vogel et al. (1993) measured $\Delta^{14} \mathrm{C}$ in fourteen pairs of dendrochronologically dated wood from South Africa and the Netherlands and calculated an offset of $5.15 \pm$ $0.59 \%$ o $\left(41 \pm 5{ }^{14} \mathrm{C} \mathrm{yr}\right)$, with the Southern Hemisphere wood giving the older dates. This value is used to correct Southern Hemisphere radiocarbon determinations for age calibration. However, Sparks et al. (1995) found no hemispheric offset in New Zealand matai (Prumnopitys taxifolia) from a single, non-crossdated tree spanning $\mathrm{AD}$ 1335-1745. Barbetti et al. (1995) reported a negligible offset in Tasmanian wood compared with European oak at 10,000-9,500 cal BP and minimal offsets between $\mathrm{AD} 1600$ and 1800 , although the ${ }^{14} \mathrm{C}$ measurements for these series lack high levels of precision (Barbetti et al. 1992, 1995).

Recently, Damon, Cheng and Linick (1989), Damon et al. (1992) and Damon (1995a,b) have identified significant differences $(c a .4-7 \%$ ) between contemporaneous tree rings in the same hemisphere from Tucson, the Olympic Peninsula of Washington State and the Mackenzie Valley in the Arctic Circle. McCormac et al. (1995) have suggested location-dependent differences in ${ }^{14} \mathrm{C}$ from contemporaneous trees in Ireland and the United States; Stuiver and Braziunas (1998) and McCormac et al. (1998) have shown variations in the value of the interhemispheric ${ }^{14} \mathrm{C}$ offset. These authors have suggested that regional effects may not be temporally constant.

In this paper, we describe a research program designed primarily to verify the existence and magnitude of the hemispheric offset in ${ }^{14} \mathrm{C}$ between New Zealand and Great Britain. The program is a collaborative effort among the radiocarbon laboratories at The Queen's University of Belfast, Northern Ireland (QUB) and the University of Waikato in New Zealand (Wk) and the tree-ring laboratories at the Department of Plant Sciences at Lincoln University in New Zealand and the Palaeoecology Centre at QUB. We are in the process of measuring $\Delta^{14} \mathrm{C}$ in successive decadal samples of dendrochronologically dated Irish/English oak and New Zealand cedar spanning the period AD 1000-1945 to investigate location dependence and the hemispheric offset. In this paper, we describe our methodology, provide the results of a preliminary intercomparison exercise designed to identify any interlaboratory differences and give preliminary results for the offset between Great Britain and New Zealand in the interval AD 1725 to 1885 . Our preliminary measurements between $\mathrm{AD} 1885$ and $\mathrm{AD}$

\footnotetext{
'The Queen's University of Belfast, School of Geosciences, Belfast, BT7 1NN, Northern Ireland

${ }^{2}$ Radiocarbon Dating Laboratory, University of Waikato, Private Bag 3105, Hamilton, New Zealand

${ }^{3}$ Plant Sciences Department, Lincoln University, Lincoln, New Zealand
} 
1935 (not discussed in detail here) indicate a hemispheric response to fossil fuel input in the Northern Hemisphere (McCormac et al. 1998).

\section{METHODS}

The intrahemispheric location-dependent differences in $\Delta^{14} \mathrm{C}$ identified by McCormac et al. (1995) are small (on the order of $2.5 \%$ ) and may be time dependent. As a consequence, intercomparison of results from different regions tends to be difficult and laboratory offsets can easily mask real atmospheric variation. The only satisfactory way to determine the magnitude of regional offsets, should they exist, is to measure $\Delta^{14} \mathrm{C}$ in contemporaneous sample pairs within a single laboratory and replicate the measurements in another laboratory. Duplication of the measurements by the two laboratories has enabled us to compare inter- and intralaboratory data sets and to obtain duplicate high-precision (HP; $\Delta^{14} \mathrm{C} \sigma \leq 2 \%$ ) curves for the validation of results. The advantage of duplicate intralaboratory measurements is that there are no external offsets to consider, hence relative differences between the ${ }^{14} \mathrm{C}$ dates of wood from both hemispheres should be real.

Three components are critical to the success of the research program: dendrochronology, wood pretreatment and analytical reproducibility.

\section{Dendrochronology}

It is critical that the wood used in $\mathrm{HP}{ }^{14} \mathrm{C}$ calibration comes from securely crossdated and well replicated tree-ring chronologies. Dendrochronological errors can easily create false offsets in the $\Delta^{14} \mathrm{C}$ values between regions or between significant sections of the calibration chronologies (Kromer $e t$ al. 1996). In designing this study we have used oak from the long-established Irish oak master chronology (Pilcher et al. 1984) and the recently developed New Zealand cedar (Libocedrus bidwillii) chronology (Xiong 1995). The dendrochronology of the oak from the British Isles has been both externally and internally cross-linked and has provided the basis for previous calibration studies (Baillie 1995; Pearson and Stuiver 1986, 1993). The oak trees actually used for the measurements shown in this paper were obtained from parkland at Shane's Castle, County Antrim, Northern Ireland $\left(54^{\circ} 44^{\prime} \mathrm{N}, 06^{\circ} 16^{\prime} \mathrm{W}\right)(\mathrm{AD} 1935-1755)$ and Sherwood Forest, England $\left(53^{\circ} 12^{\prime} \mathrm{N}, 01^{\circ} 04^{\prime} \mathrm{W}\right)(\mathrm{AD}$ 1725-1745).

The New Zealand cedar chronology is now established for the period AD 1950 to AD 1140 and is derived from 11 different sites and over 200 trees (Xiong 1995). The specific tree selected for this study was one of 43 crossdated trees from the Hihitahi State Forest, near Waiouru in the central North Island of New Zealand ( $\left.39^{\circ} 32^{\prime} \mathrm{S}, 175^{\circ} 44^{\prime} \mathrm{E}\right)$.

All wood samples were split into decadal blocks each weighing between 120 and $180 \mathrm{~g}$.

\section{Wood Pretreatment}

By necessity, the tree species used for this study was different in each of the hemispheres. We therefore sought to pretreat the wood to a reliable fraction of cellulose that would reflect the ambient atmospheric conditions at the time of growth and would not be affected by variable lignin fractions or species-specific differences. A variety of methods have been applied to pretreat wood for radiocarbon calibration because of the possibility of translocation of resins and sugars across rings (Tsoumis 1969: 60-89; Olsson 1979). The de Vries method (Stuiver and Quay 1981) utilizes treatment with dilute $\mathrm{NaOH}$ and $\mathrm{HCl}$ to remove resins, sugars and some lignins. A full description is given in Stuiver, Burk and Quay (1984), detailing the method for pretreatment to $\alpha$-cellulose used at the University of Washington, Seattle laboratory for the 1986 calibration measurements (Stuiver and Pear- 
son 1986). The Belfast laboratory used a different method involving the bleaching of the wood using sodium chlorite and $0.018 \mathrm{~N} \mathrm{HCl}$ at $70^{\circ} \mathrm{C}$ followed by charring of the cellulose at $500^{\circ} \mathrm{C}$ to produce a carbon-rich residue (Pearson and Stuiver 1986). Linick et al. (1986) pretreated bristlecone pine to holocellulose using acetic acid and sodium chlorite. For this study we have pretreated both wood types to $\alpha$-cellulose. The method used is described in detail in Hoper et al. (1998), where an investigation into the effectiveness of the sample pretreatment method is described.

\section{Radiocarbon Analysis}

Both Waikato and Belfast laboratories measure $\Delta^{14} \mathrm{C}$ by liquid scintillation counting of benzene, using the same type of spectrometers (Wallac Quantulus $1220^{\mathrm{TM}}$ ) and similar benzene synthesis systems. The Wallac Quantulus $1220^{\mathrm{TM}}$ is an optimized spectrometer designed for low-level counting (Polach et al. 1988). For high-precision measurements, the stability and performance of the Quantulus for $\Delta^{14} \mathrm{C}$ measurement may be further increased by manual control of the high voltage (HV) supply to the guard and sample photomultiplier tubes (McCormac 1992). The Waikato laboratory operates two factory-modified manual high-precision versions of the Quantulus using a similar system. One is set up using manual HV control, the other using automatic HV.

The Waikato and Belfast laboratories use different methods to obtain an analytical precision of $c a$. $\pm 2 \%$. The Belfast laboratory uses single $15 \mathrm{~mL}$ aliquots of benzene to achieve high levels of precision $( \pm 2-3 \%$ ) . Standard deviations at Belfast include the Poisson counting error and an error multiplier to account for replicate sample variability. The Waikato laboratory utilizes duplicate $7.5 \mathrm{~g}(\mathrm{ca}$. $8 \mathrm{~mL}$ ) aliquots of benzene for each equivalent single HP measurement and then combines the two measurements, provided the results are statistically representative of the same mean value. This provides a continuous measure of internal reproducibility. The precision of each decadal measurement is $c a$. $\pm 2.5 \%$, with a final mean precision for each decadal sample of $c a$. $\pm 2 \%$.

\section{Intercomparison}

We have undertaken an intercomparison exercise to quantify Wk/QUB offsets, beginning by remeasuring multiple samples of the International Reference Materials HOxI and HOxII (Long 1995). The Belfast and Waikato HOxI/HOxII activity ratios are presented in Table 1.

TABLE 1. HOxI/HOxII Activity Concentration Ratios Measured at Waikato and Belfast (error-weighted mean)

\begin{tabular}{lc}
\hline Laboratory & Ratio HOxI/HOxII \\
\hline Waikato mean & $1.2887 \pm 0.0013$ \\
Belfast mean & $1.2895 \pm 0.0008$ \\
\hline
\end{tabular}

The error-weighted mean calculated was statistically indistinguishable from the international weighted average reported by Mann (1983) of $1.2893 \pm 0.0004$.

Despite the consistency of these standards, the cedar and oak measurements made independently in Waikato and Belfast do show measurable differences. When we compare the measurements on identical oak and cedar samples, the laboratory differences are 9.1 \pm 6.4 and $10.9 \pm 5.6 \mathrm{yr}$, respectively. It seems likely that this difference may be explained in part by the use of different standards in the two laboratories (HOxII in Belfast and ANU Sucrose in Waikato). 


\section{RESULTS}

The results of both the QUB and Wk paired measurements on cedar and oak for the interval AD 1725 to 1935 are shown in Figures 1 and 2, respectively. The offsets between the cedar and oak determined independently in both laboratories are shown in Figure 3. By combining the results from both laboratories and calculating the error-weighted mean of the difference over the interval, we obtain an offset of $27.2 \pm 4.7{ }^{14} \mathrm{C}$ yr. This is less than the value reported by Vogel et al. $(1986,1993)$ and may indicate a regional difference in the hemispheric offset because in both this study and that of Vogel et al. $(1986,1993)$ the offsets were determined by intralaboratory measurements. A recent publication by Stuiver and Braziunas (1998) shows data from Chile, Tasmania and the United States that give a hemispheric offset value of $23 \pm 4 \mathrm{yr}$ for the 19th century.

\section{CONCLUSIONS}

Intralaboratory ${ }^{14} \mathrm{C}$ measurements of Southern and Northern Hemisphere wood avoid laboratory biases and enable determination of the offset in $\Delta^{14} \mathrm{C}$ between the hemispheres without reconciling interlaboratory differences. Using this protocol and producing replicate measurements in QUB and Wk of the $\Delta^{14} \mathrm{C}$ content of $\alpha$-cellulose derived from decadal samples of dendrochronologically

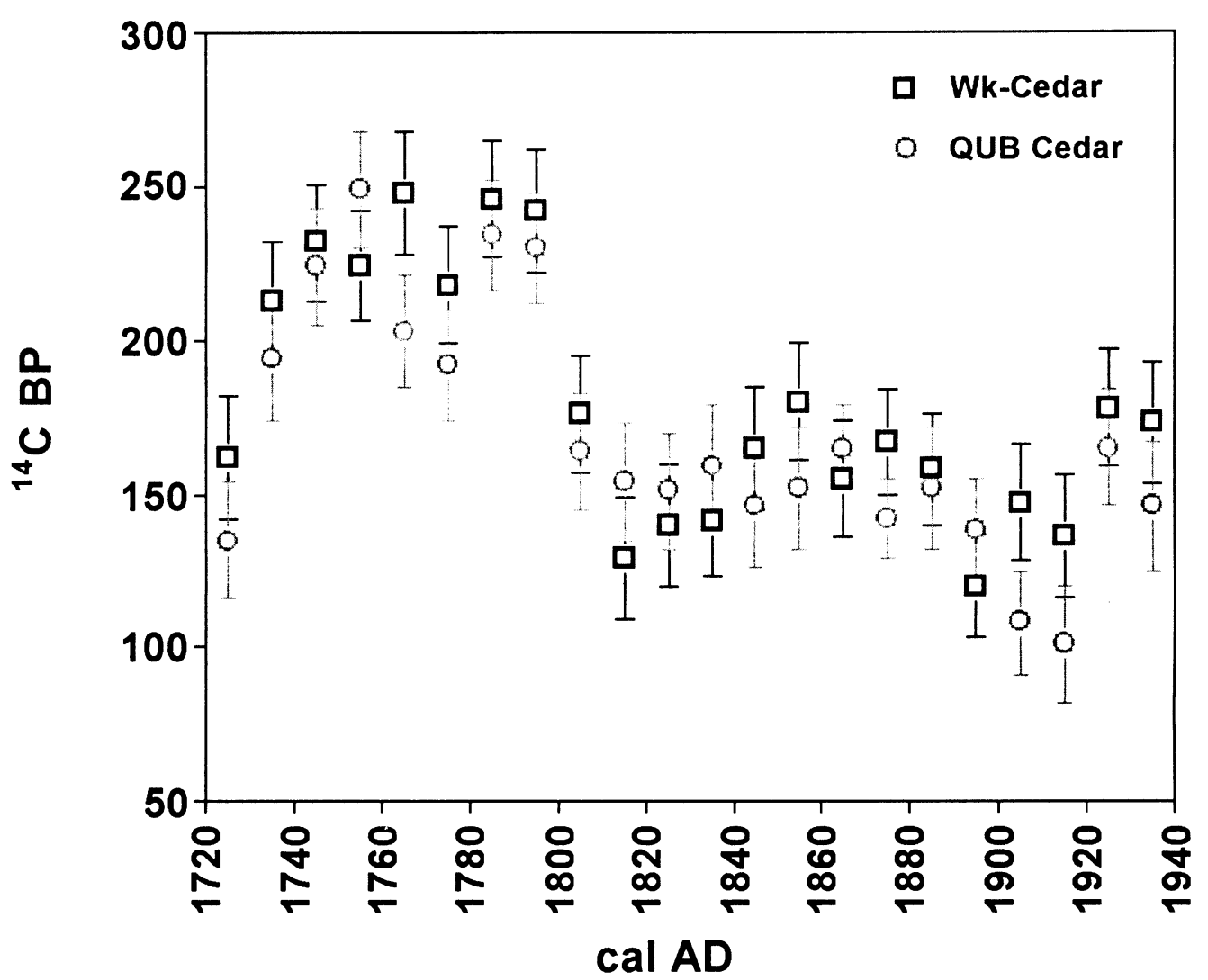

Fig. $1 .{ }^{14} \mathrm{C}$ measurements (yr BP) made at QUB and Wk on decadal blocks of cedar from New Zealand 
dated oak from Northern Ireland and cedar from the North Island of New Zealand, we have found that an offset of $3.4 \pm 0.6 \%$ o $\left(27.2 \pm 4.7{ }^{14} \mathrm{C}\right.$ yr $)$ exists between the two locations for the interval $\mathrm{AD}$ 1725 to $\mathrm{AD} 1885$.

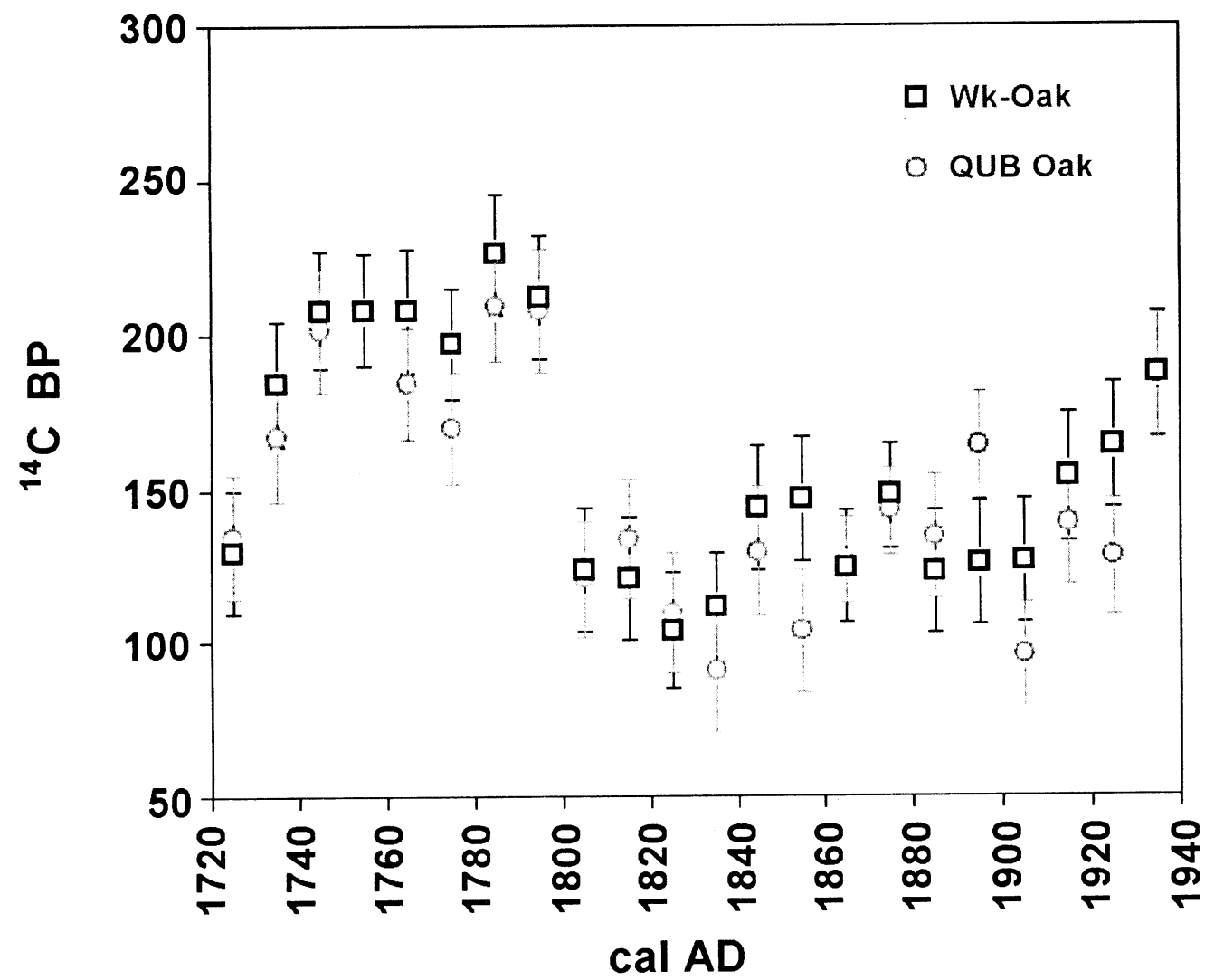

Fig 2. ${ }^{14} \mathrm{C}$ measurements (yr BP) made at QUB and Wk on decadal blocks of oak from England and N. Ireland 


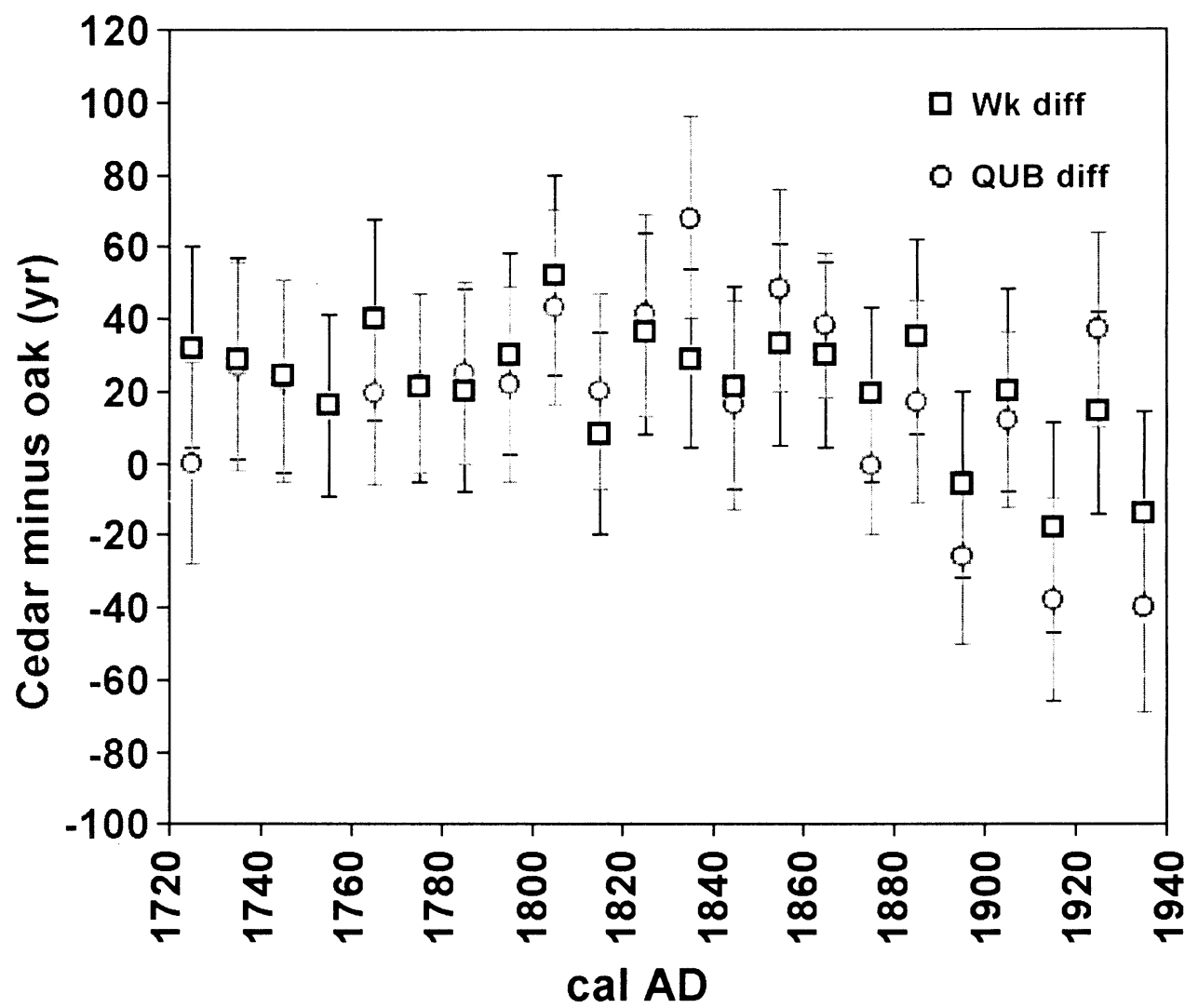

Fig 3. Hemispheric differences (yr) between individual decadal measurements of oak from the British Isles $\left(\sim 54^{\circ} \mathrm{N}\right)$ and cedar from New Zealand $\left(\sim 39^{\circ} \mathrm{S}\right)$ made at QUB and Wk

\section{REFERENCES}

Baillie, M. G. L. 1995 A Slice Through Time: Dendrochronology and Precision Dating. London, Routledge: $176 \mathrm{p}$.

Barbetti, M., Bird, T., Dolezal, G., Taylor, G., Francey, R., Cook, E. and Peterson, M. 1992 Radiocarbon variations from Tasmanian conifers: First results from late Pleistocene and Holocene logs. In Long, A. and Kra, R. S., eds., Proceedings of the 14 th International ${ }^{14} \mathrm{C}$ Conference. Radiocarbon 34(3): 806-817.

1995 Radiocarbon variations from Tasmanian conifers: Results from three Holocene logs. In Cook, G. T., Harkness, D. D., Miller, B. F. and Scott, E. M., eds., Proceedings of the 15 th International ${ }^{14} \mathrm{C}$ Conference. Radiocarbon 37(2): 361-369.

Damon, P. E. 1995a A note concerning "Location-dependent differences in the ${ }^{14} \mathrm{C}$ content of wood" by McCormac et al. In Cook, G. T., Harkness, D. D., Miller, B. F. and Scott, E. M., eds., Proceedings of the 15th International ${ }^{14} \mathrm{C}$ Conference. Radiocarbon 37(2): 829830.
Damon, P.E. 1995b Note concerning "Intercomparison of high-precision ${ }^{14} \mathrm{C}$ measurements at the University of Arizona and the Queen's University of Belfast Radiocarbon Laboratories" by Kalin et al. (1995) and the regional effect. Radiocarbon 37(3): 955-959.

Damon, P. E., Burr, G., Cain, W. J. and Donahue, D. J. 1992 Anomalous 11 -year $\Delta^{14} \mathrm{C}$ cycle at high latitudes. Radiocarbon 34(2): 235-238.

Damon, P. E., Cheng, S. and Linick, T. W. 1989. Fine and hyperfine structure in the spectrum of secular variations of atmospheric ${ }^{14} \mathrm{C}$. In Long, A., Kra, R. S. and Srdoc, D., eds., Proceedings of the 13th International ${ }^{14} \mathrm{C}$ Conference. Radiocarbon 31(3): 955-959.

Hoper, S. T., McCormac, F. G., Hogg, A. G., Higham, T. F. G. and Head, J. 1998 Evaluation of wood pretreatments on oak and cedar. In Mook, W. G. and van der Plicht, J., eds., Proceedings of the 16th International ${ }^{14} \mathrm{C}$ Conference. Radiocarbon 40(1): 45-50.

Kromer, B., Ambers, J., Baillie, M. G. L., Damon, P. E., Hesshaimer, V., Hofmann, J., Jöris, O., Levin, I., Man- 
ning, S. W., McCormac, F. G., van der Plicht, J., Spurk, M., Stuiver, M. and Weninger, B. 1996 Report: Summary of the workshop "Aspects of High-Precision Radiocarbon Calibration". Radiocarbon 38(3): 607-610.

Lerman, J. C., Mook, W. G. and Vogel, J. C. $1970{ }^{14} \mathrm{C}$ in tree-rings from different localities. In Olsson, I. U., ed., Radiocarbon Variations and Absolute Chronology: Proceedings of the Twelfth Nobel Symposium Held at the Institute of Physics at Uppsala University. Stockholm, Almquist and Wiksell: $652 \mathrm{p}$.

Linick, T. W., Long, A., Damon, P. E. and Ferguson, C. W. 1986 High-precision radiocarbon dating of bristlecone pine from 6554 to 5350 BC. In Stuiver, M. and Kra, R., eds., Calibration Issue. Radiocarbon 28(2B): 943-953.

Long, A. 1995 From the editor [NIST Standard nomenclature]. Radiocarbon 37(1): iii-iv.

Mann, W. B. 1983 An international reference material for radiocarbon dating. In Stuiver, M. and Kra, R.S., eds., Proceedings of the 11 th International ${ }^{14} \mathrm{C}$ Conference. Radiocarbon 25(2): 519-527.

McCormac, F. G. 1992 Liquid scintillation counter characterization, optimization and benzene purity correction. Radiocarbon 34(1): 37-45.

McCormac, F. G., Baillie, M. G. L., Pilcher, J. R. and Kalin, R. M. 1995 Location-dependent differences in the ${ }^{14} \mathrm{C}$ content of wood. In Cook, G. T., Harkness, D. D., Miller, B. F. and Scott, E. M., eds., Proceedings of the 15th International ${ }^{14} \mathrm{C}$ Conference. Radiocarbon 37(2): 395-407.

McCormac, F. G., Hogg, A. G., Higham, T. F. G., LynchStieglitz, J., Broecker, W. S., Baillie, M. G. L., Palmer, J., Xiong, L., Pilcher, J. R., Brown, D. and Hoper S. T. 1998 Temporal variation in the interhemispheric ${ }^{14} \mathrm{C}$ offset. Geophysical Research Letters 25: 1321-1324.

Olsson, I. U. 1979 The importance of the pretreatment of wood and charcoal samples. In Berger, R. and Suess, H. E., eds., Radiocarbon Dating. Proceedings of the Ninth International Conference, Los Angeles and La Jolla, 1976. Los Angeles, University of California Press: 135-146.

Pearson, G. W. and Stuiver, M. 1986 High-precision calibration of the radiocarbon time scale, 500-2500 BC. In Stuiver, M. and Kra, R., eds., Calibration Issue. Radiocarbon 28(2B): 839-862.

1993 High-precision bidecadal calibration of the ra- diocarbon time scale, 500-2500 BC. In Stuiver, M., Long, A. and Kra, R. S., eds., Calibration 1993. Radiocarbon 35(1): 25-34.

Pilcher, J. R., Baillie, M. G. L., Schmidt, B. and Becker, B. 1984 A 7,272-year tree-ring chronology for western Europe. Nature 312: 150-152.

Polach, H. A., Kaihola, L., Robertson, S. and Haas, H 1988 Small sample ${ }^{14} \mathrm{C}$ dating by liquid scintillation spectrometry. Radiocarbon 30(2): 153-155.

Sparks, R. J., Melhuish, W. H., McKee, J. W. A., Ogden, J., Palmer, J. G. and Molloy, B. P. J. $1995{ }^{14} \mathrm{C}$ calibration in the Southern Hemisphere and the date of the last Taupo eruption: Evidence from tree-ring sequences. In Cook, G. T., Harkness, D. D., Miller, B. F. and Scott, E. M., eds., Proceedings of the 15th International ${ }^{14} \mathrm{C}$ Conference. Radiocarbon 37(2): $155-$ 163.

Stuiver, M. and Braziunas, T. F. 1998 Anthropogenic and solar components of hemispheric ${ }^{14} \mathrm{C}$. Geophysical Research Letters 25: 329-332.

Stuiver, M., Burk, R. L. and Quay, P. D. $1984{ }^{13} \mathrm{C} /{ }^{12} \mathrm{C}$ ratios in tree rings and the transfer of biospheric carbon to the atmosphere. Journal of Geophysical Research 89: 11,731-11,748.

Stuiver, M. and Pearson, G. W. 1986 High-precision calibration of the radiocarbon time scale, 1950-500 BC. In Stuiver, M. and Kra, R., eds., Calibration Issue. Radiocarbon 28(2B): 805-838.

Stuiver, M. and Quay, P. D. 1981 Atmospheric ${ }^{14} \mathrm{C}$ changes resulting from fossil fuel $\mathrm{CO}_{2}$ release and cosmic ray flux variability. Earth and Planetary Science Letters 53: 349-362.

Tsoumis, G. 1969 Wood as raw material: Source, structure, chemical composition, growth, degradation, and identification. Oxford, Pergamon Press: 276 p.

Vogel, J. C., Fuls, A., Visser, E. and Becker, B. 1986 Radiocarbon fluctuations during the third millennium BC. In Stuiver, M. and Kra, R., eds., Calibration Issue. Radiocarbon 28(2B): 935-938.

1993 Pretoria calibration curve for short-lived samples, 1930-3350 BC. In Stuiver, M., Long, A. and Kra, R. S., eds., Calibration 1993. Radiocarbon 35(1): 7385.

Xiong, L. (ms.) 1995 A dendroclimatic study of Libocedrus bidwillii Hook F. (kaikawaka). Ph.D. thesis, Lincoln University, Canterbury, New Zealand. 